\title{
The Effectiveness of the Value Investment Theory During the COVID-19 Pandemic: Using the Heavy Asset Industry as an Example
}

\author{
Quan Zhou ${ }^{1, *}, \dagger$ Yuming Liu ${ }^{2, \dagger}$ \\ ${ }^{1}$ New York University, New York, New York 10016 (post), United States \\ ${ }^{2}$ University of Carolina, Santa Cruz, Santa Cruz, CA 95060 (post), United States \\ *Quan Zhou.Email:qz858@nyu.eduYYuming Liu.Email: yliu289@ucsc.edu
}

†These authors contributed equally.

\begin{abstract}
Value Investing Strategy is one of the most favourable investment methods. However, under the complexity and fluctuation brought by the influence of COVID-19, the effectiveness of value investing strategy remains in question. The paper uses heavy asset industry as a target industry and strive to understand the performance of value investing in such industry under the effects of the pandemic. Specifically, four companies are selected in our study to analysis their performance using value investing ratios, including two representative companies (H\&E Equipment Services, Inc., United Rentals, Inc., Sonic Automotive, Inc., and O'Reilly Automotive, Inc.) of the heavy asset industry and their competitors, which are considered as value stocks (before COVID-19). The evaluation standard ratios are grouped into four aspects, representing the company's prices, profit abilities, growth, and stabilities. The study first compares the subjects' performances in the same periods in 2019 (before COVID-19) and 2020 (after the initiation of COVID-19). In order to eliminate the noise of the influence of normal business cycles, the performance of subjects in the same periods from 2018 to 2019 are supplied as an addition to the previous data. According to the results, the subjects' performances deviate from the ideal value investing criteria as well as their expected future performance predicted based on their normal performance in the 2018 2019 period (without COVID-19's influence). Therefore, value investing strategy incurs questionable efficiency under the context of COVID-19, i.e., the relevance of value investing application ought to be reconsidered under such an abnormal economic environment.
\end{abstract}

Keywords: Value Investing Theory, Heavy asset industry, COVID-19, Automotive Industry, Rental Industry, Case Study

\section{INTRODUCTION}

Most investors use either the value investing or the growth investing approach when investing in the stock markets [1]. The value investing approach is less risky compared to the growth investing approach, which possess the potential to give better returns in the long run [2]. Value investing has been popular for decades until the COVID-19 pandemic, which has stirred things and left investors questioning whether value investing still works during the pandemic. Under such a large context of the influence of COVID-19, it is necessity to discuss the effectiveness of value investing in various industries including the heavy asset industry.
Value investing refers to trying to identify good, solid businesses that are trading below their fair value. The piece on value investing was first written by Benjamin Graham, a financier who first articulated the major principles of value investing in the 1930s and later turned it into a phenomenon [3]. Due to the advance of technology and information boom (e.g., the formation of Center for Research in Security Prices), the application of value investing started to prevail. In 1990s, it was formally defined as "using mechanical investment strategies based on simple ratios of accounting numbers to stock prices" [4]. Value investing can be compared to the careful examination of the merits of a house purchase by looking at the rental yields, construction quality as well as price comparisons with other neighbourhoods, streets, 
and cities. The strategy seeks to determine and invest in companies that are trading below their value. This is achieved through fundamental analysis methods like calculation of different balance sheet and $\mathrm{P} \& \mathrm{~L}$ ratios. Value investing investors select stocks that are undervalued and keep them for a period. As soon as share prices rise and reach their real value, they will sell them resolutely.

Value investing has had a good track record of working across different economic cycles [5]. Value investing has experienced ups and downs over the past century, but it always bounces back strongly. As Graham said in Ref. [6]: "The intelligent investor is a realist who sells to optimists and buys from pessimists". However, Graham and Dodd [7] introduced value investing with the caution of using comprehensive analysis that includes both quantitative and qualitative discussions. Fama and French (1998) is also one of the most renown analysis of value investing using the a of statistical approach, employing low $\mathrm{P} / \mathrm{E}$ and $\mathrm{P} / \mathrm{B}$ ratios as indicator for values stocks [8], which is the position that this paper partakes. Some studies argue that the effectiveness of value investing using metrics has become weaker after the introduction [4]. Others have found that purely using financial statement analysis outperform the market [9]. Absolutely, it is normal that investment strategy has not succeeded in providing investors with the proper opportunities [10]. However, experts believe that value investing, as a strategy, is valid for investors in the past supported by strong evidence [10].

The habits of companies changed drastically after COVID-19 from borrowing habits to operational processes. Almost all aspects of companies and businesses have experienced a significant change. In the future, many experts believe that companies will think twice before taking on debt [11]. Such extreme changes across different facets have the likelihood of changing the intrinsic value of companies. In this case, most investors will conduct fundamental analyses with the value investing view. Therefore, value investing is a strong strategy during and after the pandemic. In the postCOVID world, inflation is on the rise [12], i.e., value stocks are favorable approaches for this situation. As long as the inflation figures remain high, value investing will remain relevant.

On the other hand, business performance fluctuates between cycles, specifically expansions and contractions, which subsequentially influence the application of value investing. Similar research has been carried out with regards to the performances of value and growth investing under such business cycles. Based on Ref. [13], such deviation proposes cautions while executing value investing strategies to different industries. In this paper, discussions are demonstrated for a specific example of industrial companies. The validity and rationality behind using value investing theory are inquired under the influence of COVID-19 (a contraction) with the context of heavy asset industry. Value investing metrics as reference data are utilized to make sense of value investing strategy's performance before and after the occurrence of COVID-19. In addition, we propose a theoretical supposition that COVID-19 creates potential influences on the relevance, accuracy, and validity of the indication of value investing metrics under the context of heavy asset industry.

\section{DATA AND METHOD}

\subsection{Data}

For the sake of understanding the discussion issue, following four companies are chosen: H\&E Equipment Services, Inc. (ticker: HEES, referred to as "H\&E"), United Rentals, Inc. (ticker: URI; referred to as "United Rentals"), Sonic Automotive, Inc. (ticker: SAH; referred to as "Sonic"), and O'Reilly Automotive, Inc. (ticker: ORLY; referred to as "O'Reilly").

$\mathrm{H} \& \mathrm{E}$ and Sonic are heavy asset value stocks screened according to value investing metrics calculated based on financial data from 2015 to 2019. Detailed derivation of stock screening shall be found in section 3.2. United Rentals and O'Reilly are large capital competitors that are listed in the S\&P 500 with similar business line. They were chosen as comparison group to the previous two stocks to diversify the samples within the limited context by adding in industrial representing companies.

Collected data comes majorly from subject companies' relevant financial reports, e.g., posted on U.S. Securities and Exchange Commission's company 10-Q filings. The financial accounting base point of data collection is September 30th, 2020, including prices, revenue, shares outstanding and other relevant information as utilized in the obtainment of results and discussions. For cumulative financial information (e.g., net income), this paper employs the data with a duration of three months (stated as "three months ended" on all financial reports respectively). This attempt is to decrease other noise factors (e.g., seasonal business cycle) and restrain the focus on the COVID-19 influences in quarter three of 2020. The rationale for choosing quarter three specifically as an accounting period is due to the following two reasons: 1.) to allow time for lagging responses to the spike of the pandemic that happened earlier in the year (around April, according to NPR News $[14])$; 2.) the third quarter financial information is the latest filing data with respect to the time when this research is conducted.

\subsection{Method}

This paper will utilize a quantitative method to test the hypothesis that value investing metrics will be influenced under the context of COVID-19. Quantitative method 
approaches a question by testing a hypothesis that steams from an already existing theory [15] Thusly, this paper's approach and conclusion would focus less on details and more on the drawing general conclusion, utilizing statistics as well as graphs and charts to "enable comparison" [16]. In addition, this research utilizes the method of longitudinal studies aiming to capture the development of companies metrics performance before and after COVID-19's initiation to understand the potential effect of the pandemic on value investing metrics and consequentially the value investing strategy [16].

Value investing measures is utilized as indication of subject companies' performance before and after the emergence of the COVID-19 pandemic. Relevant ratios will be categorized and evaluated on three aspects: valuation, profitability, growth. The ratios relating to each section will be either calculated directly using accounting data from selected companies' filing reports or collected from public data resources for uniformity (e.g., Yahoo Finance). The metrics entailed for value stock screening in each sector are allocated as the following (adjectives inside the parenthesis are desired characteristics for that sector):

Pricing (cheap/low): P/E(TTM), P/B, P/S, EV/Sales, EV/EBITDA

Profitability (high): GP/A, ROE, ROA, Return, Dividend Yield

Growth (fast/high): Sales Growth, EBITDA growth, EPS Growth

Value investing uses the metrics above as models to value the stock price relative to its intrinsic value. Those metrics are categorized as three categories as stated before, which are measuring pricing, profitability, and growth of the company and its stock [17]. Also notice that $\mathrm{P} / \mathrm{E}$ ratio and $\mathrm{P} / \mathrm{B}$ ratio are two common indicators of value stocks, as they generally lead to stable results, according to Fama and French (1998) [4]. P/E ratio generally reflects the investors' belief in the firm's future growth momentum, while $\mathrm{P} / \mathrm{B}$ ratio exhibit the investor's expectation in the future profits generated by the firm's current assets [18]. Therefore, this paper includes profitability and growth metrics in relevance to the meanings of the $\mathrm{P} / \mathrm{E}$ and $\mathrm{P} / \mathrm{B}$ ratios (major value stock indicators) in order to present a more complete investment logic of value investing.

\subsubsection{Pricing metrics}

$\mathrm{P} / \mathrm{E}$ ratio is the abbreviation for price-earnings ratio, which is the ratio of the stock per share over the net earnings per share of the company. $\mathrm{P} / \mathrm{B}$ ratio is the abbreviation for the price-book ratio corresponding to the stock price per share over the book value (assets minus liability on the balance sheet in the accounting) per share.
$\mathrm{P} / \mathrm{S}$ ratio is the price-sale ratio that the stock price per share over the gross revenue per share of the company. $\mathrm{EV} / \mathrm{Sales}$ is the ratio of enterprise value over the revenue of the company. Unlike the book value or market capitalization of the company, enterprise value includes both market capitalization and cash. As a result, its debts on the company's balance sheet to value the business of the company. EV/EBITDA is the ratio of enterprise value over the earning before interests, taxes, depreciation, and amortization (EBITDA)

\subsubsection{Profitability metrics}

GP/A, gross profit to assets, measures profitability by calculating the gross profit of the company at one year over the total assets of the company in book value. ROE, return on equity, is the measurement of profitability which is calculated by dividing net income by the shareholder equity in book value. ROA, return on assets, measure the profitability by calculating the ratio of net income over total assets. Return, return on price, is calculated by dividing the difference in the price of a stock between the previous year to the current year by the price of current year. Dividend yield is calculated by dividing dividends over the stock price per share at a given time.

\subsubsection{Growth metrics.}

Sales growth calculated the annual growth rate of the revenue. EBITDA growth calculate the annual growth rate of EBITDA. EPS growth calculates the annual growth rate of the earning per share of the stock. 


\subsection{Understanding Valuation}

\section{RESULTS AND DISCUSSION}

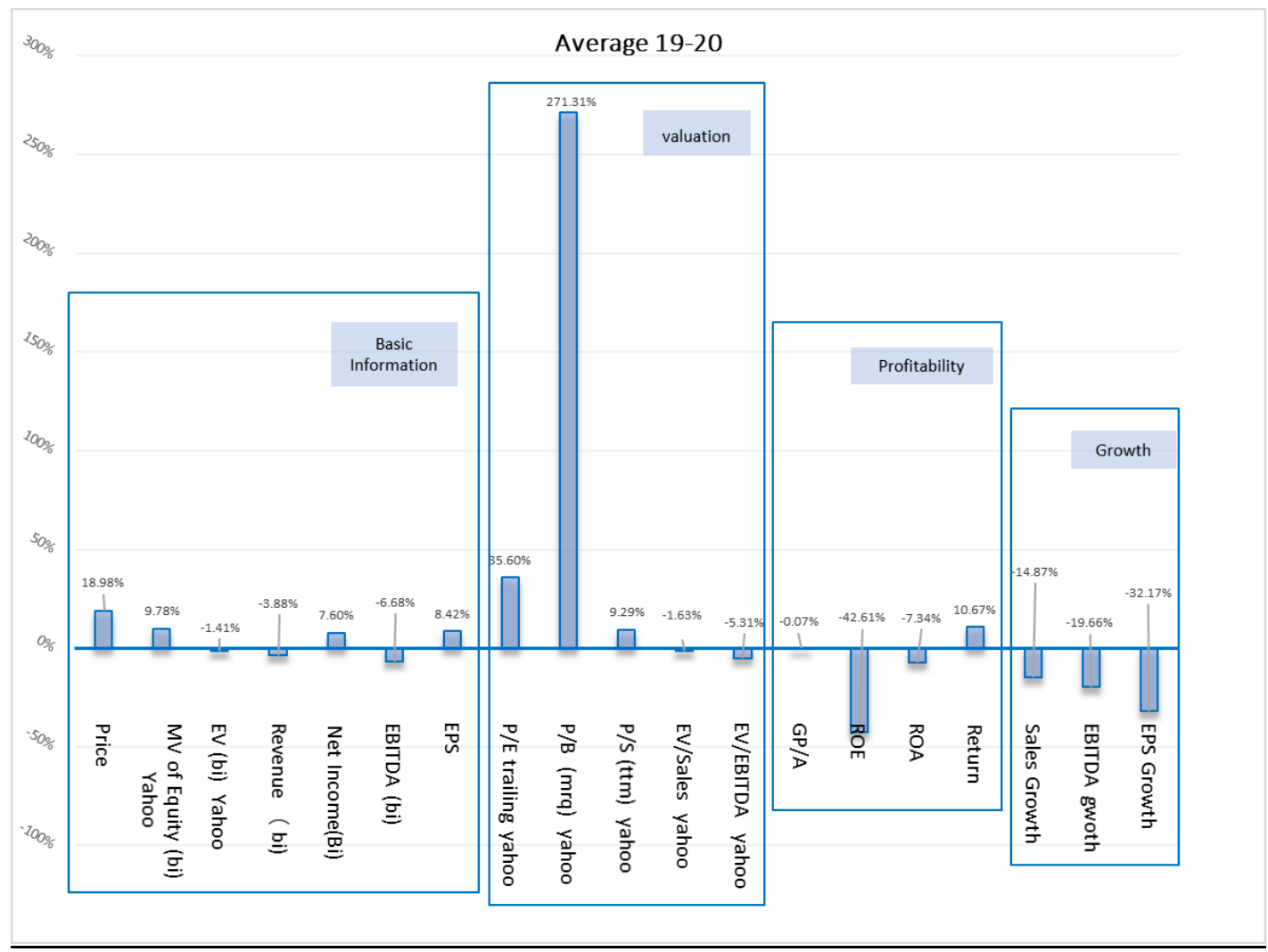

Figure 1. Average Changes of all subjects' financial metrics from 2018 to 2019

\subsubsection{Changes in metrics from 2019 to 2020 violates Value Investing Logics}

For the sake of investigating variation of the four groups of metrics and value investment method application under the influence of COVID-19, changes in each metrics are calculated presented in the Figure 1. To compare, the collected data are restricted to only 2019 Q3 and 2020 Q3, which is the most current quarter under COVID's continuing effects. Thus, discussion on growth stability will be restricted to the changes from 2019 Q3 to 2020 Q3. As shown in Figure 1, the metrics are grouped into four segments: basic information, price, profitability and growth. The results will be analysed in each section to reflect potential changes that COVID brings.

Firstly, the average of the four firms does not experience decrease in either price, net income and EPS, which suggests that company with heavy assets might not have experienced significant setbacks in pricing competition. However, it should be noticed that revenue and EBITDA both decrease, which indicates that the pandemic slows down consumptions on commodities resulting in revenue slides as well as the companies' profit generating abilities. COVID might also cause various difficulties during production. For example, the delayed work plan in early 2020 that productions have to be terminated, which might reflect larger effects in heavy assets companies as they are usually production focused. One reason for the decline of EBITDA might be attributed to the continuing maintenance costs and piling up expanse from idle production plants without revenue. As a result, EBITDA, or the companies' earning abilities experienced general decrease.

Secondly, in the valuation sector, one observes that $\mathrm{P} / \mathrm{E}$ increase by $35.60 \%, \mathrm{P} / \mathrm{S}$ by $9.29 \%$ and $\mathrm{P} / \mathrm{B}$ of a large increase of $271.31 \%$. These spiking of the three metrics could all reflect the market's attitude towards these stocks, where investors gradually consider them more expansive. On the other hand, EV/Sales and EV/EBITDA are negative could be ascribed to the decrease in revenue, which leads to the whole metrics decrease. Regardless, the increase in valuation of stocks reflects that average investors regards stocks during the Pandemic more expansive to buy.

Regarding the profitability, a general trend of profit decrease is presented in the profitability sector. Among all metrics, ROE decreased almost $42.61 \%$ despite increase in return, which is highly correlated to prices. GP/A and ROA both experience decrease of different degrees $(-0.07 \%$ and $-7.34 \%$, respectively). The increasing return on price might correspond to the rising 
price. The rising stock price making the return on price higher might exhibit only a monetary nature instead of real indication of profitability growth. The disagreement between profitability ratios and the return $(\mathrm{GP} / \mathrm{A}, \mathrm{ROE}$ and ROA moving in the opposite direction of return's) shows the irrationality of the market. It is abnormal that investors are purchasing companies with low profitability with high prices. The baseline logic of value investing (buy low and sell high) seems to disaccord with the market movement. Besides, it should be mentioned that the two of the four subjected sample companies except O'Reilly are considered value stocks (explained in section 3.2). The general trend shows that such a portfolio with heavy weighted value stocks performs the opposite way to the prediction of value investing theory. In other words, it again incurs question on the validity of such theory under the specific influence of COVID-19.
As for the fourth section, a cohesive trend of profitability growth decreasing is observed: sales, EBITDA, EPS growth decreased by $14.87 \%, 19.66 \%$, $32.17 \%$, respectively. Such universal reductions in all three metrics act as a side evidence that revenue and profit decrease despite the increase in price, compared to the supposed low price, high growth value investment logic. Meanwhile, as previously mentioned, a portfolio with majority value stocks should illustrate at least relatively stable growth in profitability. The sharp decrease in profitability growth of the subject portfolio stands against such expectation. Thus, the value investing strategy might not be in relevant under a pandemic influenced economic period.

\subsubsection{Comparison between 2018 to 2019 and} 2019 to 2020

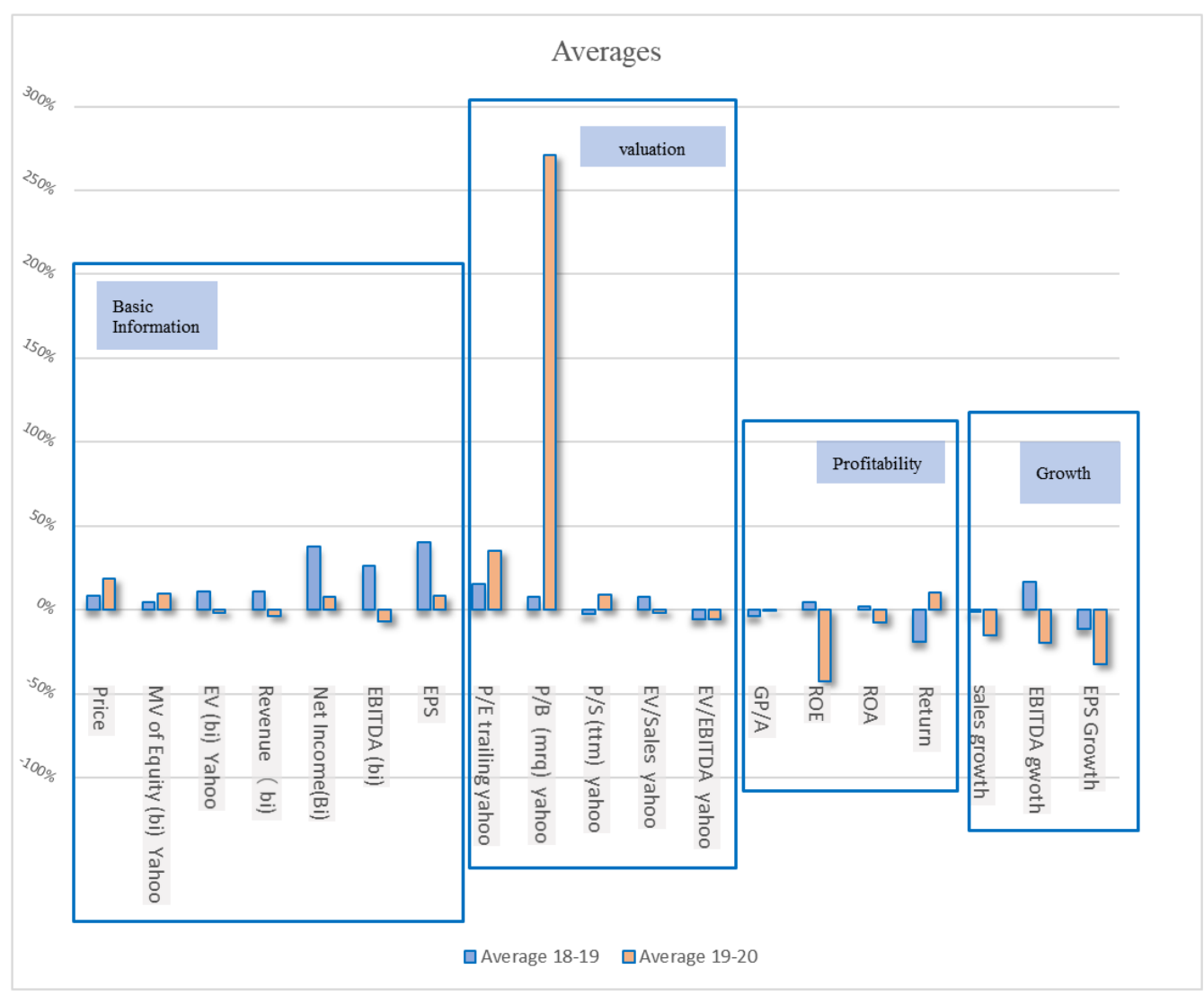

Figure 2. Average Changes of all subject's financial metrics - comparison between 2018 2019 and 2019 2020

To ensure the analysis of the performance is relevant to the COVID-19 rather than a normal business cycle, the comparison between performance changes in quarter 3, 2019 and quarter 3, 2020 is again compared (depicted in Figure 2). The data measures the performance differences between Q3 of 2018 to Q3 of 2019 and compares it to the differences between Q3 of 2019 to Q3 of 2020 for all four companies. This paper treats changes from 2018 to 2019 as indication of how stocks performance varies during normal business cycle and changes from 2019 to 2020 as representing how stocks performance fluctuated during the Pandemic period. The averages are calculated from the sum of the four subjected companies for each metric. Primarily, it could be noticed that revenue, net income, EBITDA and EPS are all growing positively from 2018 to 2019 of the average subjected companies. Such a performance should be normally expected for value stocks as the fundamentals of the companies move towards a positive direction. Compared to the previous year, the current pandemic influence year, 2020, exhibits a growth that is much lower, or even negative growth. Such behaviour suggests that value investing expectations 
are not fulfilled, further questioning the validity of value investing strategy under the context of COVID-19.

Similarly, in the valuation section, $\mathrm{P} / \mathrm{E}$ and $\mathrm{P} / \mathrm{B}$ ratio from the previous year is observed to be significantly lower than the current COVID-19 period. The low valuation ration should be considered normal for value stocks, as they are the basic indication for a cheap purchase according to value investing theory. However, the valuation hike in year 2020, again disqualifying the subjected companies from being value stocks, indicating the irrelevant of value investing strategy.

Furthermore, looking at the profitability of the companies, changes in ROE and ROA from 2018 to 2019 are also more positive compared to changes from 2019 to 2020. This suggests that the subjected portfolio should experience positive profitability under normal situation. Nevertheless, due to the influence of COVID-19, the expectation according to the value investing theory (value stocks experience high profitability) is violated, as proved by the decrease in profit metrics from 2019 to 2020. Similarly, opposite of the expected growth in profitability, growth trend in the pandemic period is significantly more negative than the growth in regular period, again disqualifying the expectation for value stocks.

To take such observation further, Figure 3 illustrates the performance of a portfolio excluding United Rentals and O'Reilly, which is composed with only two value stocks. One noticed that the changes for different periods follow the same pattern as stated above. Specifically, revenue and profit generating ability decreased while valuation factors such as $\mathrm{P} / \mathrm{E}$ and $\mathrm{P} / \mathrm{B}$ increased. Besides, ROE, ROA and return on price decreased along with a uniformed falling in growth and profitability. Under normal business period, H\&E and Sonic are supposed to be investment candidates under value investing strategies, showing positive profitability and growth. However, within the period of COVID-19, their performance seems to deviate from the value investing stock screening criteria, again adding doubts on the effectiveness of value investing strategy under abnormal economic background.

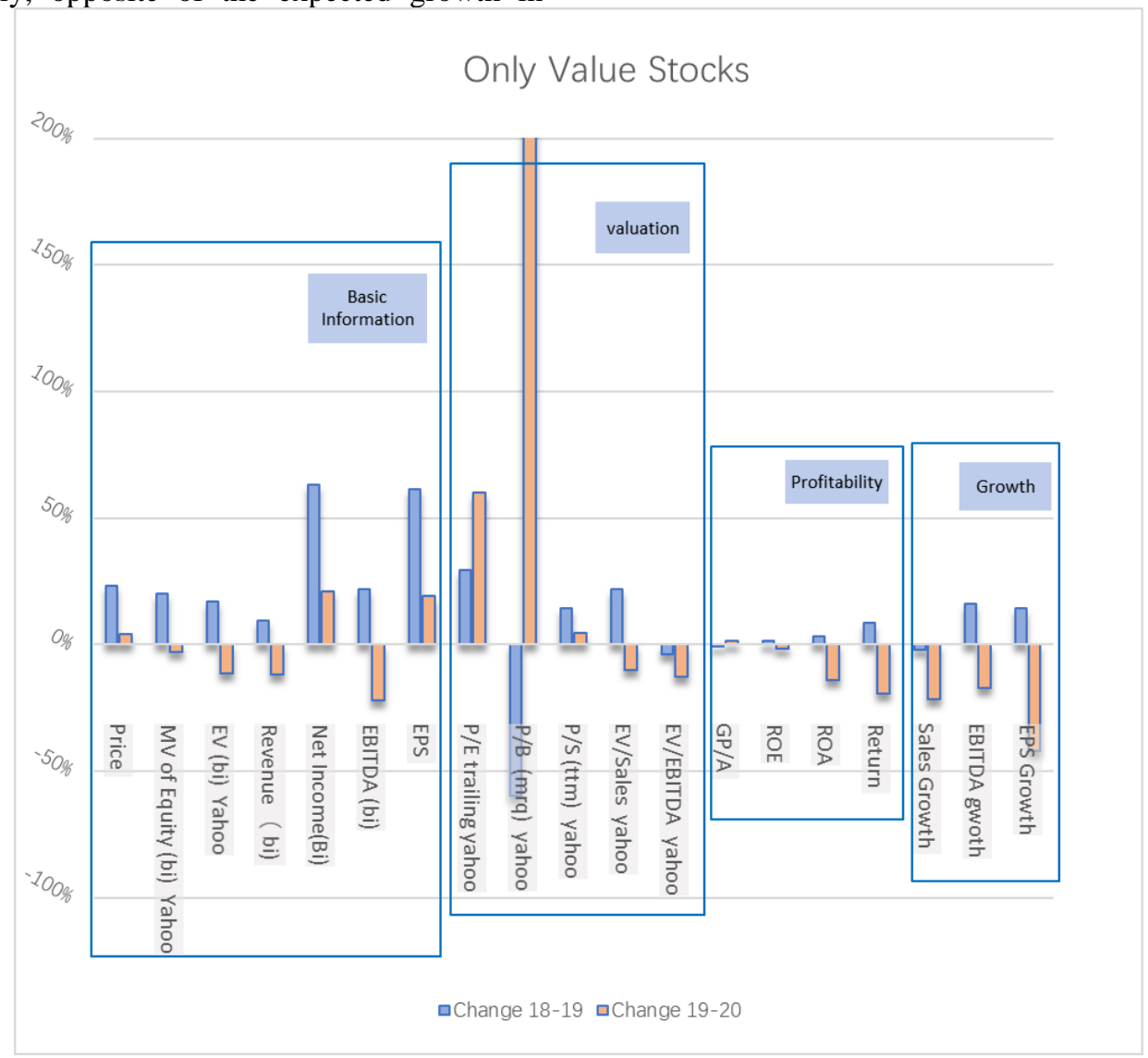

Figure 3. Average Changes of only value stocks subjects financial metrics - comparison between 2018 2019 and 2019 2020.

\subsection{Why are $H \& E$, Sonic and United Rental Value Stocks}

3.2.1 H\&E:
In 2019, H\&E has a $\mathrm{P} / \mathrm{E}$ ratio of 13.81 and an EV/EBITDA of 5.45 (refer to Table 1), which is relatively lower compare to similar competitors (see Explanations). Therefore, H\&E is a cheap stock especially considering 
its profitability and growth potential, as will be explained hereafter.

H\&E has an exceptional performance in 2019 regarding its profitability. Compares to the general group (see Explanations), H\&E's gross profit to asset (GP/A) ratio is $37.63 \%$ ( $1.5 \mathrm{x}$ of median), a one-year return of $63 \%$ (4.5x of median), and a dividend yield of $3.29 \%$ (1.2x of median), which of all are significantly higher than competitors (refer to Table 4 in Graphs and Charts).

Besides exceptional return, H\&E exhibits impressive growth potential as proven by its 2019's growth factors: its revenue grows $8 \%$ (median: $2.42 \%$ ), EBITDA grows $17.12 \%$ (median: $1.95 \%$ ) and EPS grow $13.6 \%$ (median: $6.86 \%$ ) (refer to Table 3). In this case, it possess advantages (except for the general average of revenue growth, which is likely to be an outlier) against its peers and close competitors. From a comparative standpoint, $\mathrm{H} \& \mathrm{E}$ presents reasonable superiority in most ratios of profitability and growth under comparison with peer competitors with either similar $\mathrm{P} / \mathrm{E}$ ratio or market capital in the same industry, suggesting its vibrant momentum generating excess earnings in the future (refer to Table 1 and Table 2).

Table 1. Metrics comparable with companies of similar $\mathrm{P} / \mathrm{E}$ ratio with $\mathrm{H} \& \mathrm{E}$

\begin{tabular}{|l|l|l|l|l|l|l|l|l|l|}
\hline \multicolumn{7}{|c|}{ Comparable with United Rentals and Caterpillar -- Similar P/E } \\
\hline & P/E & P/B & EV/Sales & EV/EBITDA & $\begin{array}{l}\text { Sales } \\
\text { Growth } \\
18-19\end{array}$ & $\begin{array}{l}\text { EBITDA } \\
\text { Growth } \\
18-19\end{array}$ & $\begin{array}{l}\text { EPS } \\
\text { Growth } \\
18-19\end{array}$ & $\begin{array}{l}\text { Gross } \\
\text { Profit/Assets }\end{array}$ & Return 18-19 \\
$\begin{array}{l}\text { United } \\
\text { Rentals }\end{array}$ & 11.04 & 1.82 & 2.62 & 5.72 & $16.20 \%$ & $14.09 \%$ & $15.17 \%$ & $28.3 \%$ & $62.65 \%$ \\
\hline Caterpillar & 13.75 & 2.02 & 2.07 & 9.11 & $1.68 \%$ & $1.16 \%$ & $4.68 \%$ & $24.3 \%$ & $0.00 \%$ \\
\hline H\&E & 13.81 & 1.91 & 1.88 & 5.45 & $8.83 \%$ & $17.12 \%$ & $13.62 \%$ & $37.63 \%$ & $2.72 \%$ \\
\hline
\end{tabular}

Shifting gears to a discussion about the stability of H\&E's growth, as shown in the growth trends graph below (refer to Figure 4). One sees that H\&E's growth rates in sales and EBITDA in the last five years are

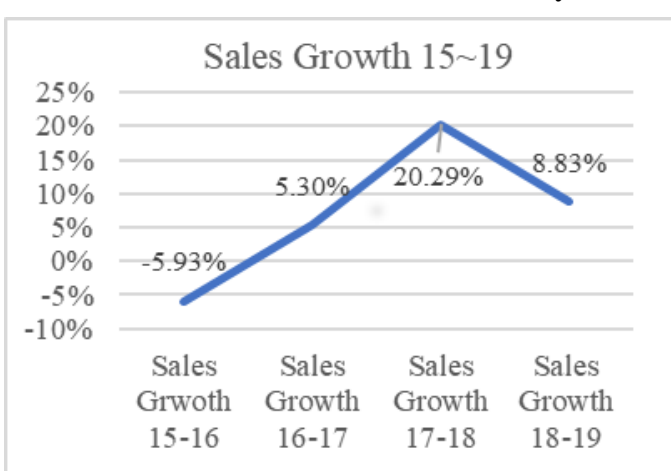

(a) majorly positive and project generally upwards tendencies despite not necessarily the most stable (i.e., a flatter trend line).

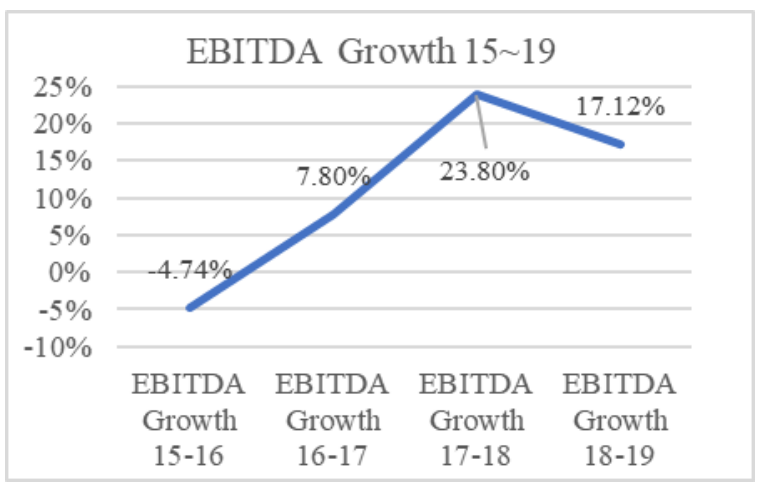

(b)

Figure 4. Sales Growth (a) and EBITDA Growth Trends (b) from 2015 to 2019 for H\&E

Again, referring to Figure 4, the decline in growth momentum in 2019, as in H\&E's Q4 earnings call, may be caused by the balancing of demand and supply, which could be understood as a market self-adjustment facing the fast growth in 2018. Nonetheless, it is still worth emphasizing that they have all been positive in the last 4 years despite a slight decrease in growth rates. Besides, the risk of growth volatility could be balanced out by the relatively high growth amount and the generally upward impulsion. Overall, H\&E presents to be a strong value stock candidate.
Explanations:

"general value stock group" / "general": Firms with $\mathrm{MV}>1 \mathrm{~B}$ and $\mathrm{P} / \mathrm{E}$ in between 5 15;

"similar competitors" / "selected competitors":

UNITED RENTALS INC; ALAMO GROUP INC; MCGRATH RENTCORP; HERC HOLDINGS INC; GENCOR INDUSTRIES INC; MANITEX INTERNATIONAL INC; CATERPILLAR INC 
Table 2. Ratios Comparisons for firms with similar market capital (Alamo Group Inc. and Herc Holdings Inc.) with $\mathrm{H} \& \mathrm{E}$

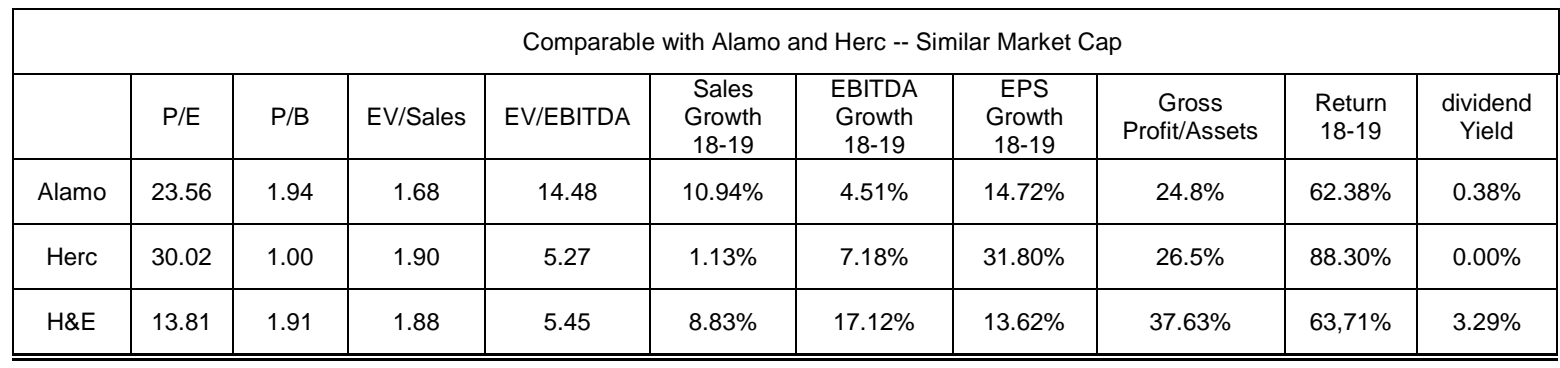

Table 3. Ratios Comparisons for firms with Market Value > 1Billion and P/E between 5 and 15

\begin{tabular}{|c|c|c|c|c|c|c|c|c|c|c|}
\hline \multicolumn{11}{|c|}{ Metrics in 2019 -- General (MV > 1B and P/E btw 5 15) } \\
\hline & $\mathrm{P} / \mathrm{E}$ & $\mathrm{P} / \mathrm{B}$ & EV/Sales & EV/EBITDA & $\begin{array}{c}\text { Sales } \\
\text { Growth } \\
18-19 \\
\end{array}$ & $\begin{array}{c}\text { EBITDA } \\
\text { Growth } \\
18-19 \\
\end{array}$ & $\begin{array}{c}\text { EPS } \\
\text { Growth } \\
18-19 \\
\end{array}$ & $\begin{array}{c}\text { Gross } \\
\text { Profit/Assets }\end{array}$ & $\begin{array}{l}\text { Return } \\
18-19\end{array}$ & $\begin{array}{l}\text { dividend } \\
\text { Yield }\end{array}$ \\
\hline AVG & 11.03 & 2.03 & 1.92 & 8.21 & $24.60 \%$ & $3.06 \%$ & $21.83 \%$ & $29.12 \%$ & $14.77 \%$ & $2.68 \%$ \\
\hline Median & 11.10 & 1.26 & 1.25 & 7.63 & $2.42 \%$ & $1.95 \%$ & $6.86 \%$ & $24.87 \%$ & $12.23 \%$ & $2.11 \%$ \\
\hline $\mathrm{H} \& \mathrm{E}$ & 13.81 & 1.91 & 1.88 & 5.45 & $8.83 \%$ & $17.12 \%$ & $13.62 \%$ & $37.63 \%$ & $63,71 \%$ & $3.29 \%$ \\
\hline
\end{tabular}

Table 4. Ratios Comparisons for firms in the same industry as H\&E Equipment:

\begin{tabular}{|c|c|c|c|c|c|c|c|c|c|c|}
\hline \multicolumn{11}{|c|}{ Metrics in 2019 -- Group } \\
\hline & $\mathrm{P} / \mathrm{E}$ & $\mathrm{P} / \mathrm{B}$ & EV/Sales & EV/EBITDA & $\begin{array}{c}\text { Sales } \\
\text { Growth } \\
18-19\end{array}$ & $\begin{array}{c}\text { EBITDA } \\
\text { Growth } \\
18-19\end{array}$ & $\begin{array}{c}\text { EPS } \\
\text { Growth } \\
18-19\end{array}$ & $\begin{array}{c}\text { Gross } \\
\text { Profit/Assets }\end{array}$ & $\begin{array}{l}\text { Return } \\
18-19\end{array}$ & $\begin{array}{l}\text { dividend } \\
\text { Yield }\end{array}$ \\
\hline Avg & 14.33 & 1.56 & 1.91 & 9.22 & $3.14 \%$ & $-1.30 \%$ & $-6.36 \%$ & $25.80 \%$ & $42.88 \%$ & $1.05 \%$ \\
\hline Median & 15.32 & 1.83 & 1.89 & 7.41 & $4.98 \%$ & $5.84 \%$ & $-5.02 \%$ & $25.66 \%$ & $55.53 \%$ & $0.19 \%$ \\
\hline $\mathrm{H} \& \mathrm{E}$ & 13.81 & 1.91 & 1.88 & 5.45 & $8.83 \%$ & $17.12 \%$ & $13.62 \%$ & $37.63 \%$ & $63,71 \%$ & $3.29 \%$ \\
\hline
\end{tabular}

\subsubsection{Sonic:}

By comparing with certain company group's stocks, Sonic Automotive seems to be a more competitive stock. This company had a current (2019) market capitalization of 1.3 billions in 2019 .

In 2019, the P/E ratio of Sonic Automotive is 9.37, which compares closely to that of China Automotive Systems and Group 1 Automotive (refer to Figure 5) Although the market is willing to pay slightly lower P/E for Sonic Automotive than other close competitors, the value is close to others. In this case, Sonic Automotive is also a strong stock with prospects of better prices to come.

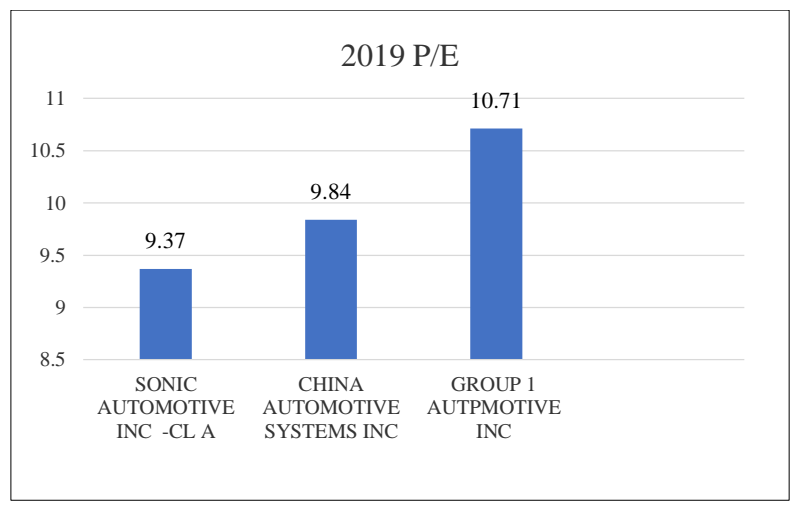

Figure 5. P/E ratio comparison for Sonic and its competitors

A better measure is EV/EBITDA because it is not affected by the changes in the capital structure. Figure 6 illustrates that sonic auto's EV/EBITA is lower than the other automotive company. Thus, Sonic is cheaper than the other automotive company. This means that compared to the close competitors, Sonic Automotive is 
considerably cheaper and could be undervalued, indicating that the investor can acquire the company for a lower value than the actual value.

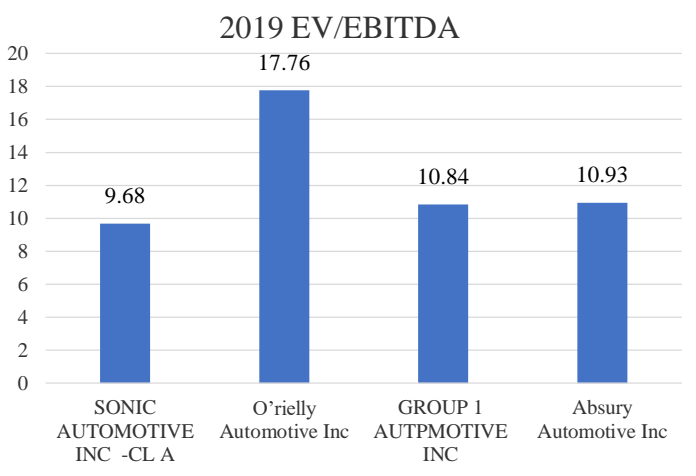

Figure 6 EV/EBITDA ratio comparison for Sonic and its competitor in 2019

Moreover, Sonic's dividend yield is higher than competitors in the same industry (refer to Figure 7). The dividend yield of Sonic Automotive was $1.29 \%$ in 2019, the highest amongst its competitors. It means that in 2019, Sonic Automotive was more worthwhile to invest in the automotive industry. On the other hand, Sonic's dividend yield presents an overall upward momentum, giving more confidence in its potential increase in return (refer to Figure 8).

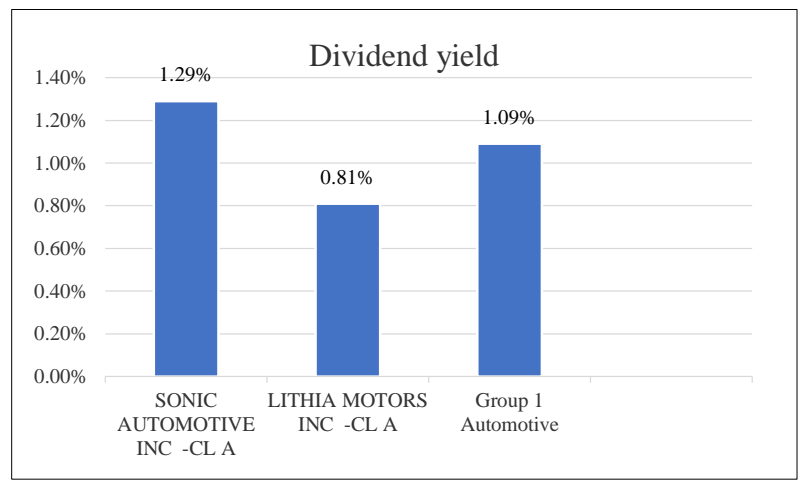

Figure 72019 Dividend Yield Comparison;

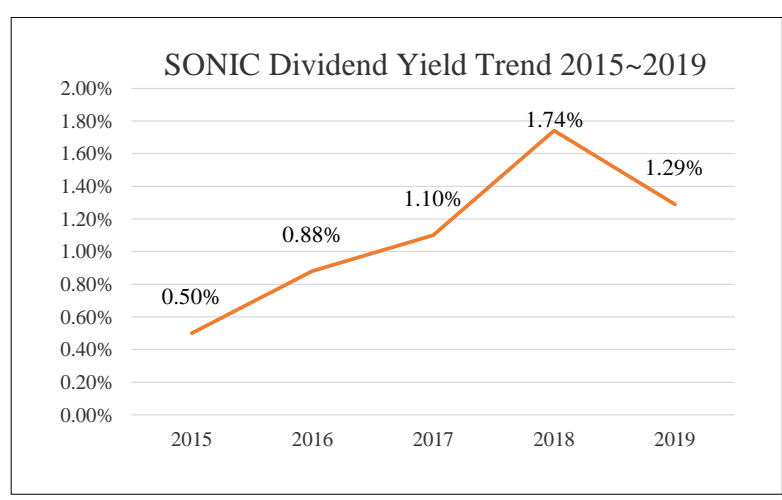

Figure 8 Sonic's Dividend Yield Trend 2015 2019

Comparing Sonic's profitability with its competitor Lithia Motors, Inc, although Lithia Motors, Inc performed slightly better in terms of sales growth from 2018 to 2019 (refer to Figure 9), Sonic has a much higher EBITA Growth rate (refer to Figure 10). In other words, it means that Sonic has lower operating expenses and higher earnings than Lithia Motors, Inc. Gross profit/assets for Sonic Automotive also excel that of Lithia Motors, Inc in 2019 (refer to Figure 11).

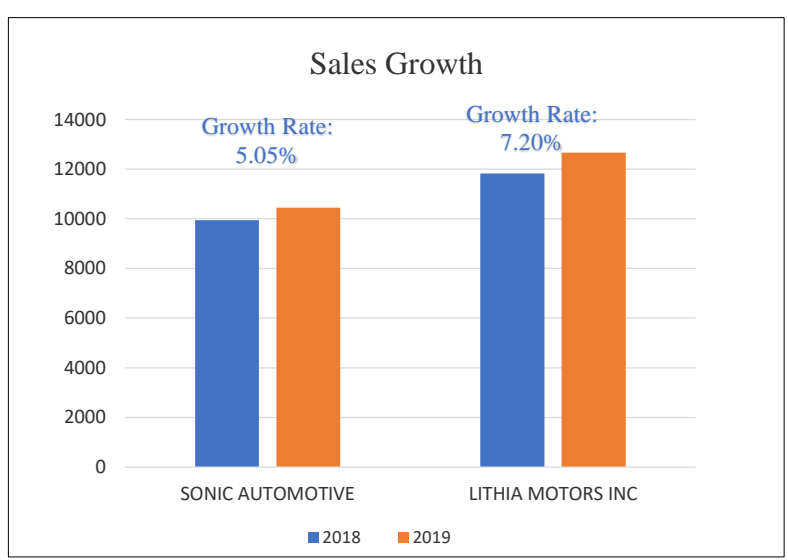

Figure 9 Sales Growth Comparison - Sonic and Lithia Motors, Inc.

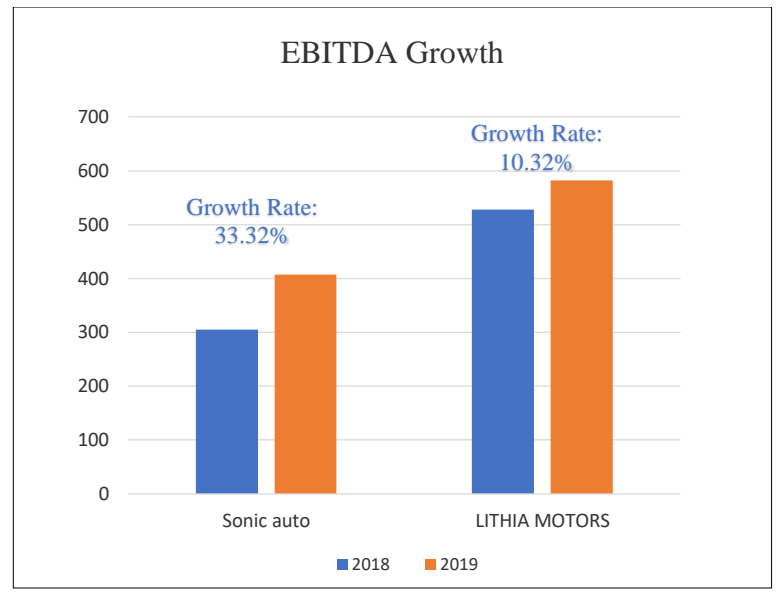

Figure 10 EBITDA Growth Comparison - Sonic and Lithia Motors, Inc.

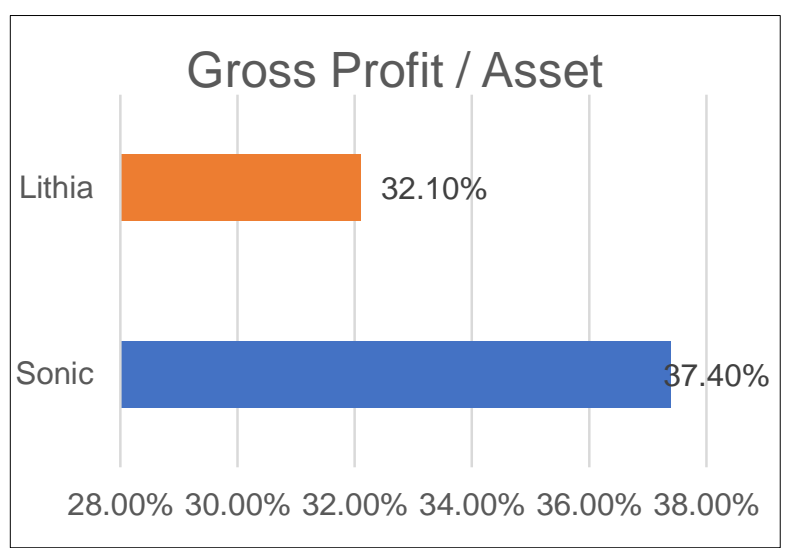

Figure 11 Gross Profit/Asset comparison between Sonic and Lithia Motors, Inc. in 2019 
In general, Sonic is cheaper than its selected competitors in terms of lower P/E and EV/EBITDA ratios, but outperform competitor in dividend yield and GP/A ratio, which suggest that Sonic is a company with lower price and higher profitability. Sonic's profitability growth also outperform its competitor, while its growth trend is positive and relatively stable. Sonic could therefore be considered a competitive value stock candidate.

\section{CONCLUSION}

In summary, we investigate the effectiveness of value investing application under abnormal economic environment based on the metrics performance for heavy asset industry before and after the occurrence of COVID19. Four subjected companies' performance are analysed before and after the hit of the pandemic. Specifically, we first found its financial standings from the three dimensions of value investing (pricing, profitability, growth) deviating from the ideal value investing criteria. Subsequently, to eliminate the possibility of an error caused by regular business cycles, a comparison has been presented between, data from the influential period of COVID-19 (2019 2020) and those in an unaffected period (2018 2019). The results are in line with the pattern observed in the first part. In detail, desired companies with low valuation, high profitability, and fast growth all perform oppositely in different level under the exposure to the pandemic. Thus, there are sufficient reasons to cast doubt on the relevance of Value Investing application under the influence of unusual economic factor. These results add to the complexity for the realworld applicable scenarios of value investing theory, where deviation from the theory occurs when encountering irregular economic shock (e.g., COVID19). By means of combining extraordinary real-world economic situation with theoretical base of the Value Investing Theory, we attempt to understand the width and strength of the theory's application. In a sense, our outcomes widen possible theoretical context as well as variate the applicable scenes of the Value Investing Theory. In real world investments practices, the evaluation standards of this paper offer a guidance for investment as well as corporations' future strategies.

\section{REFERENCES}

[1] Greenwald B C, Kahn J, Bellissimo E, et al. Value investing: From graham to buffett and beyond[M]. John Wiley \& Sons, 2020.

[2] Battisti E, Miglietta N, Salvi A, et al. Strategic approaches to value investing: a systematic literature review of international studies[J]. Review of International Business and Strategy, 2019.

[3] Wigglesworth, R. (2020). Coronavirus crisis: Does value investing still make sense? Retrieved from https://www.ft.com/content/00c722d6-760f-4871a927-2c564fe 17276

[4] Kok U W, Ribando J, Sloan R. Facts about formulaic value investing[J]. Financial Analysts Journal, 2017, 73(2): 81-99.

[5] Asness C, Frazzini A, Israel R, et al. Fact, fiction, and value investing[J]. The Journal of Portfolio Management, 2015, 42(1): 34-52.

[6] Graham, Benjamin. The Intelligent Investor REV Ed. HarperCollins, 2015.

[7] Graham, Benjamin, David Le Fevre Dodd, and Sidney Cottle. Security analysis. New York: McGraw-Hill, 1934.

[8] Fama, Eugene F., and Kenneth R. French. "Value versus growth: The international evidence." The journal of finance 53.6 (1998): 1975-1999.

[9] Noma M. Value investing and financial statement analysis[J]. Hitotsubashi journal of commerce and management, 2010: 29-46.

[10] Potter, B. (2020, May). THE UPS\&DOWNS OF VALUE INVESTING DURING COVID-19. Nikko Asset Management.

[11] SARAVANAN, P. (2020, September 15). Stock selection: Value investing is essential in today's market. The Financial Express.

[12] Bogdanova, K. (2020). Growth versus value investing in a COVID-19 world. $\mathrm{v}$

[13] Seung-Woog Kwag, \& Lee, S. W. (2006). Value in vesting and the business cycle. Journal of Financial Planning, 19(1), 64-66,68-71: 64

[14] Adeline, Stephanie, et al. "Coronavirus Is Surging: How Severe Is Your State's Outbreak?" NPR, NPR, 16 Jan. 2021.

[15] Bell E, Bryman A, Harley B. Business research methods[M]. Oxford university press, 2018.

[16] Saunders M, Lewis P, Thornhill A. Research methods forbusiness students[J]. Essex: Prentice Hall: Financial Times, 2003.

[17] Liang D, Lu C C, Tsai C F, et al. Financial ratios and corporate governance indicators in bankruptcy prediction: A comprehensive study[J]. European Journal of Operational Research, 2016, 252(2): 561-572.

[18] Bratland E, Mäki D. An empirical study into value investing on the Stockholm stock exchange[J] 2014:19. 